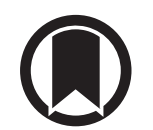

CrossMark

\title{
Increased respiratory symptoms in COPD patients living in the vicinity of livestock farms
}

\author{
Floor Borlée ${ }^{1,2}$, C. Joris Yzermans ${ }^{2}$, Christel E. van Dijk², Dick Heederik ${ }^{1}$ and \\ Lidwien A.M. Smit ${ }^{1}$
}

Affiliations: ${ }^{1}$ Institute for Risk Assessment Sciences, Utrecht University, Utrecht, The Netherlands. ${ }^{2}$ Institute for Health Services Research (NIVEL), Utrecht, The Netherlands.

Correspondence: Floor Borlée, Institute for Risk Assessment Sciences, Yalelaan 2 "De Uithof", 3584 CM, Utrecht, The Netherlands. E-mail: f.borleeduu.nl

ABSTRACT Several studies have investigated the effect of livestock farm emissions on the respiratory health of local residents, but results are inconsistent. This study aims to explore associations between the presence of livestock farms and respiratory health in an area of high-density livestock farming in the Netherlands. We focused especially on associations between farm exposures and respiratory symptoms within subgroups of potentially susceptible patients with a pre-existing lung disease.

In total, 14875 adults (response rate 53.4\%) completed a questionnaire concerning respiratory health, smoking habits and personal characteristics. Different indicators of livestock farm exposures relative to the home address were computed using a geographic information system.

Prevalence of chronic obstructive pulmonary disease (COPD) and asthma was lower among residents living within $100 \mathrm{~m}$ of a farm (OR 0.47, 95\% CI 0.24-0.91 and OR 0.65, 95\% CI 0.45-0.93, respectively). However, $>11$ farms in $1000 \mathrm{~m}$ compared to fewer than four farms in $1000 \mathrm{~m}$ (fourth quartile versus first quartile) was associated with wheezing among COPD patients (OR 1.71, 95\% CI 1.01-2.89). Using general practitioners' electronic medical records, we demonstrated that selection bias did not affect the observed associations.

Our data suggest a protective effect of livestock farm emissions on the respiratory health of residents. Nonetheless, COPD patients living near livestock farms reported more respiratory symptoms, suggesting an increased risk of exacerbations.

@ERSpublications

COPD patients living near livestock farms reported more respiratory symptoms, suggesting a high risk of exacerbations http://ow.ly/P8ttB

This article has supplementary material available from erj.ersjournals.com

Received: Feb 132015 | Accepted after revision: June 222015 | First published online: Aug 062015

Support statement: This study was supported by a grant from the Lung Foundation Netherlands (grant number: 3.2.11.022). Funding information for this article has been deposited with FundRef.

Conflict of interest: Disclosures can be found alongside the online version of this article at erj.ersjournals.com

Copyright OERS 2015 


\section{Introduction}

Intensive livestock production is associated with environmental impacts and public health issues on a global scale [1]. Concerns about emerging antibiotic resistance and outbreaks of zoonotic diseases, such as avian influenza [2] and Q fever [3] have drawn attention to various risks to human health that may result from livestock farms near residential areas. Neighbouring residents can potentially be exposed to dust, infectious agents, microbial toxic agents (endotoxins), allergens and irritant gases such as ammonia and hydrogen sulfide emitted by livestock farms [1]. Various studies have measured elevated levels of livestock farm-related agents in the vicinity of stables, especially downwind [4-8].

Exposure to endotoxins, cell-wall fragments of Gram-negative bacteria, has been associated with pro-inflammatory responses and adverse respiratory health effects [9]. Paradoxically, a farm childhood is associated with a lower prevalence of asthma and atopy $[10,11]$. Higher and more diverse environmental exposures to microbial components seem to play a role in this protective effect on IgE-mediated asthma and allergies $[12,13]$.

Two ecological studies reported a higher prevalence of wheezing and physician-diagnosed asthma among children and adolescents attending schools near confined swine-feeding operations [14, 15]. However, ELLIOT et al. [16] found a lower frequency of asthma in schoolchildren associated with higher community-level livestock farm exposures. Studies on the effect of livestock farm exposures assessed at the individual level are scarce. In a cross-sectional study in 565 children from Iowa (USA), a higher environmental exposure to animal feeding operations was associated with asthma outcomes [17]. A panel study among 101 nonsmoking adults in North Carolina (USA) showed that self-reported hog odour and measured air pollutants were associated with acute physical symptoms [18]. In a rural area of Germany, living within $500 \mathrm{~m}$ of $>12$ animal houses was a predictor of self-reported wheeze and decreased forced expiratory volume in $1 \mathrm{~s}$ [19]. Conversely, a Dutch study found mostly inverse associations between the presence of livestock near the home address and asthma, allergic rhinitis and chronic obstructive pulmonary disease (COPD), based on 92548 electronic medical records (EMRs) from general practitioners (GPs) [20]. However, a comparison of the EMRs of patients in rural Dutch areas with high and low densities of livestock farms suggested more airway infections, cough and pneumonia among asthma and COPD patients in areas with high livestock densities, which could be indicative of an increased risk of exacerbations [8]. Indeed, patients with pre-existing respiratory diseases seem to respond with a greater intensity to air pollution from livestock farms in experimental studies [21, 22]. Therefore, we hypothesise that livestock farm emissions may particularly affect potentially susceptible patients with a pre-existing lung disease.

The number of studies on the effect of (individually estimated) livestock farm exposure on respiratory health of local residents are limited and results are inconsistent. We performed a survey based on a large sample size, with a validated and widely used questionnaire to assess respiratory health, which enabled us to explore respiratory diseases and self-reported respiratory symptoms. Our aim was to 1) investigate associations between livestock farm exposures and respiratory health in residents; and 2) focus especially on associations between livestock farm exposures and self-reported respiratory symptoms within subgroups of potentially susceptible patients. Since subjects were recruited via GPs, we had the unique opportunity to investigate selective response by comparing the EMRs of responders and nonresponders. This research is part of the VGO (Farming and Neighbouring Residents' Health) study.

\section{Methods}

\section{Study population}

A cross-sectional study was conducted among residents living in the eastern part of the province of Noord-Brabant and the northern part of the province of Limburg, a highly populated rural area in the Netherlands with a high density of livestock farms. In the Netherlands, every resident is obliged to be on the list of just one GP, who acts as a gatekeeper to secondary care. Therefore, all Dutch inhabitants can be reached by using the patient lists of GPs. Residents were selected by a two-stage selection procedure. First, GPs located in the study area in 2012 were selected on predefined registration quality criteria as described earlier [23] and were asked to collaborate in the study. In total, 24 GPs met these criteria and 21 agreed to participate. In the second stage of the selection procedure, patients from the selected GP practices were invited to participate in the study if they met the following inclusion criteria: 1) living in the eastern part of Noord-Brabant or the northern part of Limburg; 2) inhabitant of a municipality with $<30000$ residents; and 3) aged 18-70 years. Of the eligible patients, one person per home address was randomly selected. In total, 28163 subjects received a questionnaire. The questionnaires were accompanied by a letter from the GP that stated the name and birthday of the selected subject to ensure that the selected person would complete the questionnaire. Figure 1 presents a flow chart of the selection procedure of the study population. Questionnaires for 294 subjects were undeliverable, and were subtracted from the total number of invited patients. The total number of responders was 14882 , resulting in a response of $53.4 \%$. Analyses 


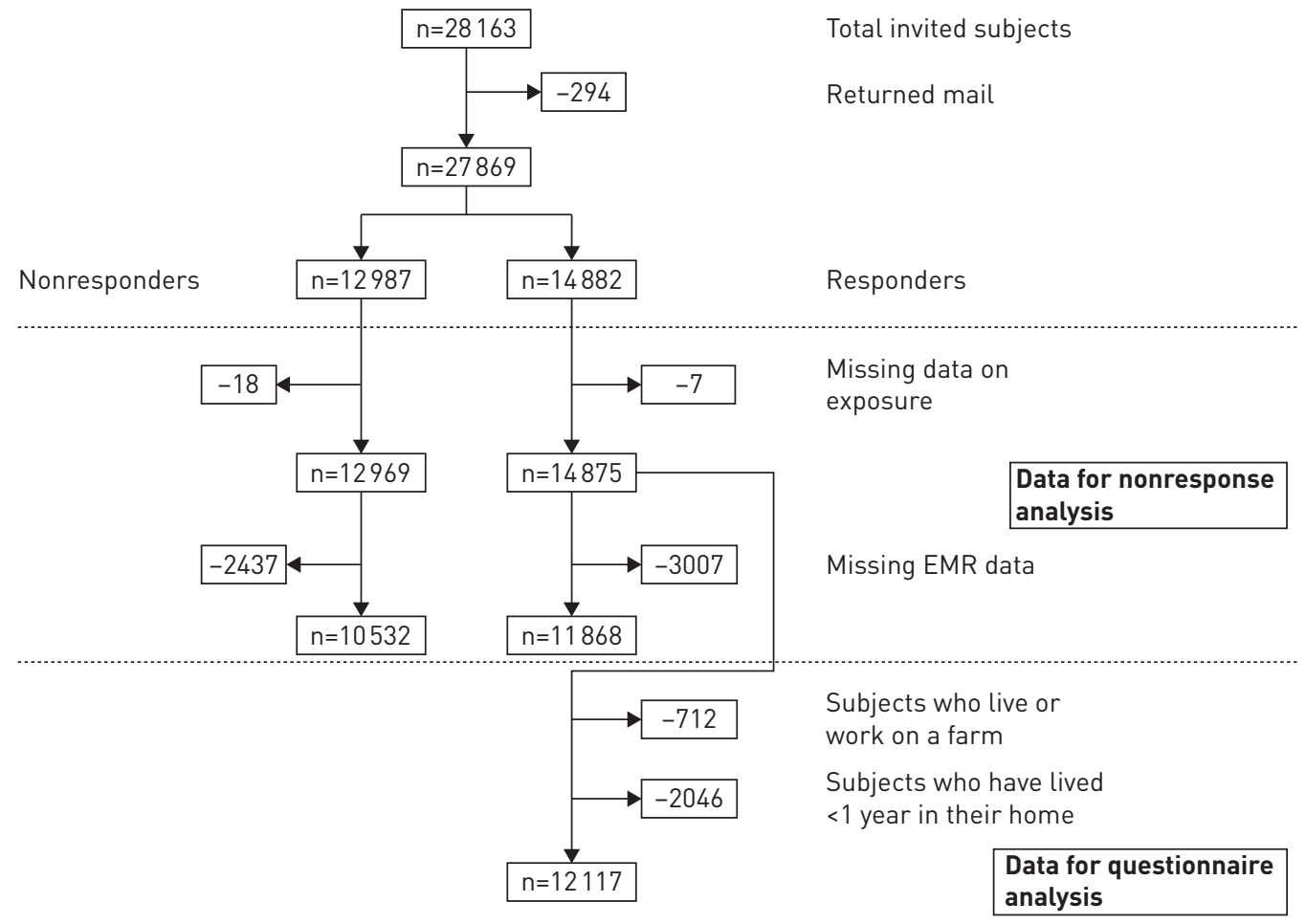

FIGURE 1 Flow chart of the data collection. Data for the nonresponse analysis included subjects with data available on exposure. When comparing electronic medical records (EMRs), only subjects with data available on EMRs were included. Data for the questionnaire analysis included subjects with data available on exposure, who were not living or working on a farm and who had lived $>1$ year in their current home.

were conducted on 12117 responders, after excluding farmers (those who reported to be living or working on a farm) and subjects who lived at their home address for $<1$ year, since we assumed that their exposure period was too short.

\section{Questionnaire}

The questionnaires were sent in November 2012. After 2 weeks, a reminder was sent. The two-page questionnaire contained questions on respiratory health, smoking habits, age, sex, whether subjects were living or working on a farm and the number of years living in their current home. Questions on respiratory health were adopted from the European Community Respiratory Health Survey (ECRHS)-III screening questionnaire [24] (online supplementary table S1).

\section{Exposures to livestock farms}

Exposure to livestock farms was computed for each subject. Information on farm characteristics in the study area was derived from the provincial databases of mandatory environmental licences for keeping livestock in 2012. These databases contain data on number and type of animals, geographic coordinates of farms and estimated fine dust emissions from each farm per year on the basis of farm type and number of animals. Addresses of subjects were geocoded. Distances between the home address and all livestock farms within $500 \mathrm{~m}$ and $1000 \mathrm{~m}$ radii were determined using a geographic information system (ArcGis 10.1; Esri, Redlands, CA, USA). The following farm exposure variables were studied for each subject: 1) distance (m) to the nearest farm (continuous variable and quartiles (Q));2) total number of farms within $500 \mathrm{~m}$ and $1000 \mathrm{~m}$ (quartiles); 3) presence of a specific livestock farm type within $500 \mathrm{~m}$ and $1000 \mathrm{~m}$ (pigs, poultry, cattle, goats and mink) (binary variables); and 4) inverse-distance weighted fine dust emissions from all farms within $500 \mathrm{~m}$ and $1000 \mathrm{~m}$ (continuous variables) as described previously [20], and in the online supplementary methods $\mathrm{S} 1$.

\section{Nonresponse analysis}

To study potential selection bias, age, sex, morbidity data and farm exposure estimates of responders and nonresponders were compared in subjects with EMR and exposure data available (fig. 1). EMRs were available through the GPs, who all participated in the Netherlands Institute for Health Services Research primary care database and agreed to participate in the study [25]. EMRs contain data at the patient level. 
The International Classification of Primary Care (ICPC) [26] was used to define asthma, COPD and allergic rhinitis for responders and nonresponders. Chronic diseases asthma (R96) and COPD (R91 or R95), were defined as $\geqslant 1$ ICPC code found in the 2010-2012 EMRs. Allergic rhinitis (R97) was defined as $\geqslant 1$ ICPC code found in 2011-2012.

\section{Data analysis}

Data were analysed using SAS 9.4 (SAS Institute Inc., Cary, NC, USA) and R version 3.0.2 (www.r-project.org).

First, we investigated selective response to the questionnaire, and to what extent risk estimates were biased as a result of self-selection. Multiple logistic regression was used to analyse whether a response to the questionnaire (dependent variable) was associated with livestock farm exposure estimates and morbidity data based on EMRs, with adjustment for age and sex (independent variables). Furthermore, we compared associations between different exposure estimates and asthma, COPD and nasal allergies (from EMRs) in the total "source" population, in all responders (including farmers) and in responders excluding farmers.

Logistic regression models were used to explore associations between farm exposure estimates (independent variables) and self-reported COPD, current asthma and nasal allergies (dependent variables) in responders. Analyses were adjusted for age, sex and smoking habits (never-smoker, ex-smoker or current smoker). The presence of a farm animal species was adjusted for the presence of other farm animal species. We expected a negligible effect of the GPs on self-reported outcomes, and therefore we decided not to adjust for clustering across practices. Moreover, results obtained by generalised estimating equations (exchangeable correlation and clustering by practice) were very similar to analyses that were not adjusted for clustering.

Analyses of current asthma were stratified by nasal allergies (as a proxy for atopy) to assess the effect of exposure on "atopic" and "nonatopic" asthma [27]. Separate analyses were undertaken for susceptible subgroups: individuals with self-reported COPD, current asthma or nasal allergies. In addition, associations between farm exposure estimates and the use of inhaled corticosteroids (ICS) in COPD patients were studied. COPD is a progressive illness which develops most often in people aged $\geqslant 40$ years. We assumed that reported COPD diagnosis was more reliable in patients who reported an age of $\geqslant 40$ years at diagnosis. In a sensitivity analysis, only subjects who were aged $\geqslant 40$ years at COPD diagnosis were included.

The shape of the relationships between wheeze and exposure variables within susceptible subgroups was studied using a penalised regression spline using the (default) "thin plate" basis as implemented in the mgcv (mixed generalised additive model computation vehicle) $\mathrm{R}$ package. Selection of smoothing parameters was based on the unbiased risk estimator criterion (a scaled version of the Akaike information criterion).

\section{Ethical aspects}

Patients' privacy was ensured as described previously [20]. In short, medical information and address records were kept separate at all times by using a trusted third party. The VGO study protocol was approved by the medical ethical committee of the University Medical Centre Utrecht (Utrecht, the Netherlands).

\section{Results}

Nonresponse analysis

Characteristics of responders and nonresponders are summarised in table 1. Responders were older than nonresponders (mean age 50.4 versus 42.8 years) and women were more often willing to participate. Responders lived closer to livestock farms than nonresponders (mean distance to the nearest farm 475 versus $498 \mathrm{~m}$ ), the mean number of farms within $1000 \mathrm{~m}$ was higher for responders (8.1 versus 7.4) and responders were more often living near specific farm animals. Although the prevalence of GP-registered COPD was slightly higher among responders, an inverse association was found with being a responder (OR 0.81, 95\% CI 0.69-0.96) after adjustment for age and sex. GP-registered allergic rhinitis was positively associated with being a responder after adjusting for age and sex (OR 1.28, 95\% CI 1.14-1.44). Overall, selection bias did not seem to affect associations between different farm exposure estimates and morbidity based on EMR data (online supplementary table S2). All associations in the total invited ("source") population and in the responder populations (including and excluding farmers) showed a similar magnitude, with overlapping confidence intervals, and had a similar direction.

\section{Associations between livestock farm exposures and respiratory outcomes}

The prevalence of self-reported asthma, COPD and nasal allergies (table 2) were higher than that based on EMR (table 1). Associations between the covariates (age, sex and smoking) and COPD, asthma and nasal allergies showed expected patterns (table 2). Several indicators of livestock farm exposures were inversely associated with current asthma and COPD; minor associations were found with nasal allergies (table 2). Adjustment for age, sex, smoking and the presence of specific farm animals did not change the results (unadjusted data not shown). Participants living very close to a farm ( $<290 \mathrm{~m}, \mathrm{Q} 4)$ had significantly lower 
TABLE 1 Comparison of characteristics of responders and nonresponders on exposure variables and electronic medical records (EMRs)

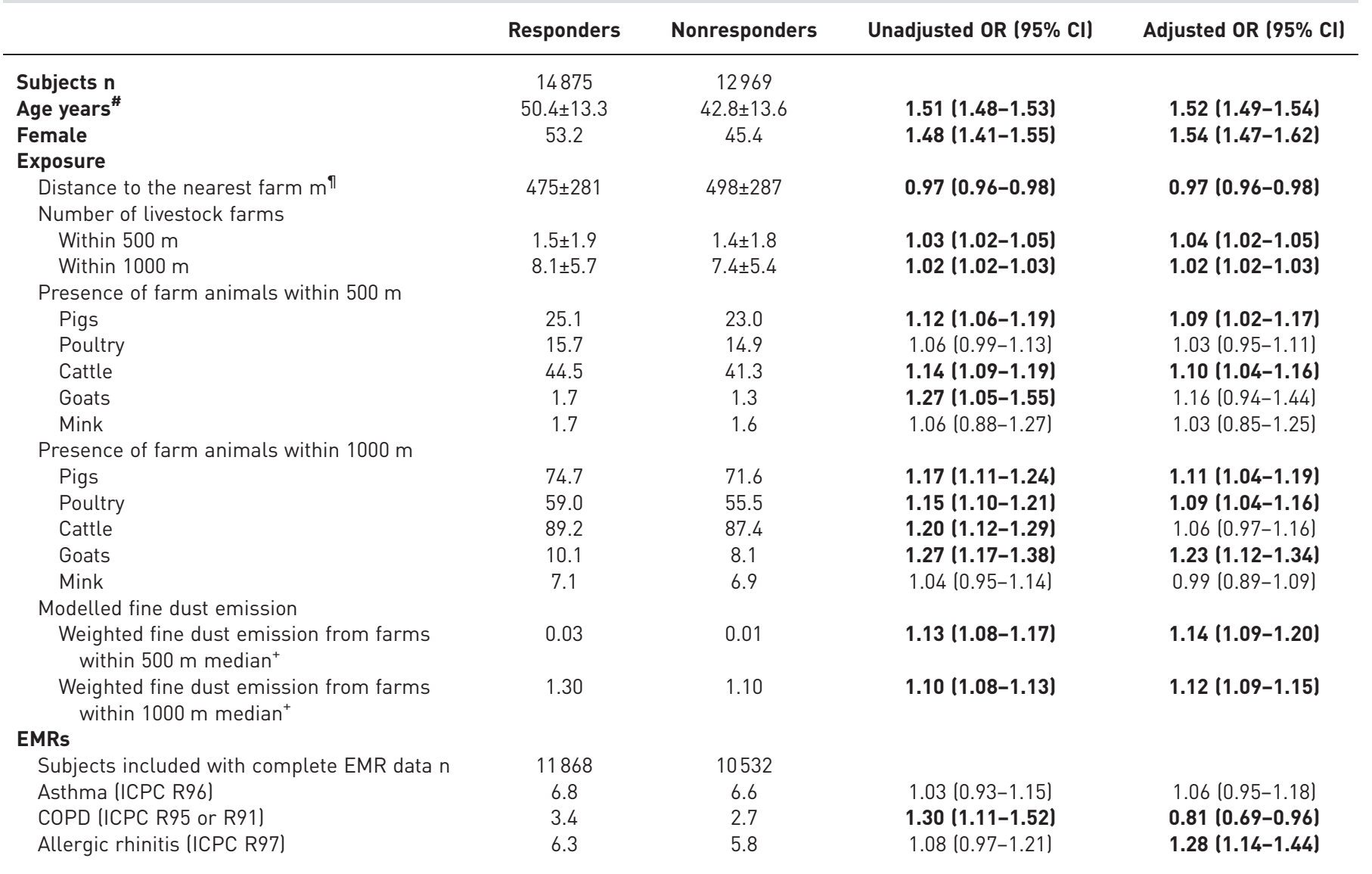

Data are presented as mean \pm SD or $\%$, unless otherwise stated. OR $(95 \% \mathrm{CI})$ were adjusted for age and sex. The likelihood of being a responder is modelled for different characteristics with logistic regression The presence of farm animals was also adjusted for the presence of other types of farm animals. Bold type indicates statistical significance $(p<0.05)$. ICPC: International Classification of Primary Care; COPD: chronic obstructive pulmonary disease. " : OR $(95 \% \mathrm{Cl})$ for an increase per 10 years; ${ }^{\uparrow}$ : OR $(95 \% \mathrm{Cl})$ for an increase per $100 \mathrm{~m}^{+}{ }^{+}$: OR $(95 \% \mathrm{Cl})$ for an interquartile range (IQR) increase in log-transformed exposure. IQR for In (fine dust) for farms within $500 \mathrm{~m} 7.54 \mathrm{~g} \cdot y e a r^{-1} \cdot \mathrm{m}^{-2}$, corresponding to a 1881 -fold increase (exposure 7.54) for nontransformed values and IQR for ln (fine dust) for farms within $1000 \mathrm{~m} 3.08 \mathrm{~g} \cdot y e a r^{-1} \cdot \mathrm{m}^{-2}$, corresponding to a 22 -fold increase for nontransformed values.

odds for current asthma, COPD and nasal allergies compared to participants living $>640 \mathrm{~m}$ (Q1) from the nearest farm. A statistically significant test-for-trend was found between the quartiles of the minimal distance to the nearest farms and current asthma, COPD and nasal allergies. The presence of a livestock farm within $100 \mathrm{~m}$ of the home address was significantly negatively associated with COPD (OR 0.71, 95\% CI 0.51-0.98) and current asthma (OR 0.65, 95\% CI 0.45-0.93). Analysis of specific animals around the home address showed inverse associations between the presence of pigs within $500 \mathrm{~m}$ and the presence of goats within $1000 \mathrm{~m}$ and current asthma.

When analyses of current asthma were stratified by nasal allergies (as a proxy for atopy) a positive association was found for presence of poultry at $500 \mathrm{~m}$ and atopic asthma (online supplementary table S3). However, the presence of mink at $500 \mathrm{~m}$ and goats at $1000 \mathrm{~m}$ showed negative associations with atopic asthma. Nonatopic asthma was only significantly negatively associated with the presence of pigs within $500 \mathrm{~m}$.

Associations of livestock farm exposure and respiratory symptoms within susceptible subgroups Wheezing among COPD patients was positively associated with several indicators of livestock farm exposures (table 3). Living at 290-450 m (Q3) and 450-640 m (Q2) from the nearest farm compared to living $>640 \mathrm{~m}$ (Q1, reference) from a farm was significantly associated with current wheeze in COPD patients (Q3 OR 1.65, 95\% CI 1.05-2.59; Q2 OR 2.17, 95\% CI 1.32-3.57). The spline in figure 2 illustrates a nonlinear association between a decreasing probability of wheezing when living $\geqslant 500 \mathrm{~m}$ from a farm. Living in an area with a high density of livestock farms (>11 farms within $1000 \mathrm{~m}, \mathrm{Q} 4)$ was also associated 
TABLE 2 Associations of livestock farm exposures and chronic obstructive pulmonary disease (COPD), current asthma and nasal allergies in 12117 questionnaire responders

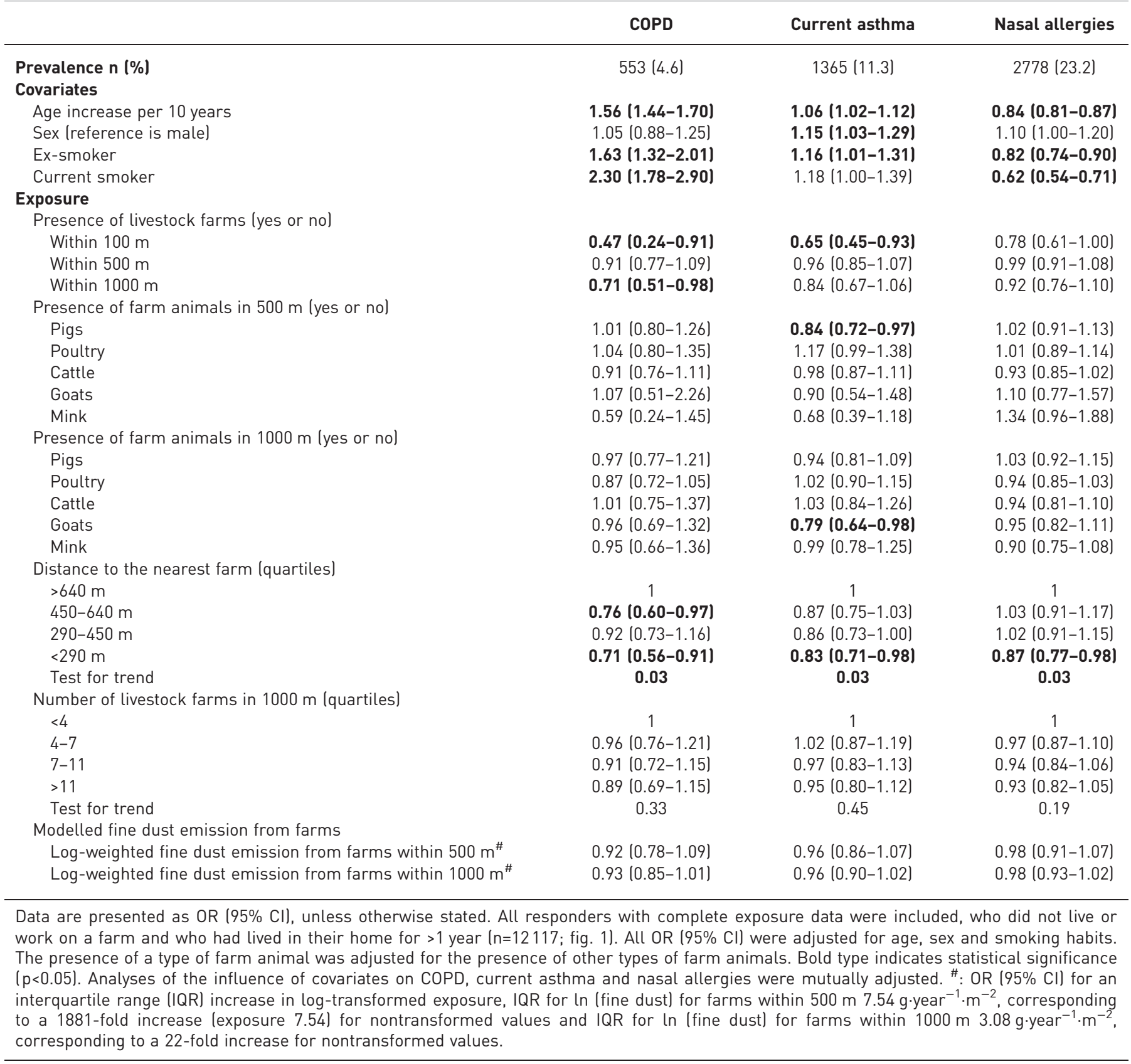

with more wheezing in COPD patients (OR 1.71, 95\% CI 1.01-2.89; table 3). No associations were observed between livestock farm exposure variables and wheezing within current asthma and nasal allergy patients.

The presence of at least one cattle farm within $500 \mathrm{~m}$ was significantly associated with an increased OR for usage of ICS (OR 1.50, 95\% CI 1.01-2.23) (online supplementary table S4). In addition, a positive nonsignificant association with usage of ICS was found among COPD patients with $>11$ farms within $1000 \mathrm{~m}$ of the home address (Q4) compared with fewer than four farms (Q1), but a significant association was seen with $>12$ farms within 1000 m (OR 1.71, 95\% CI 1.08-2.71, result not shown).

\section{Sensitivity analyses}

Sensitivity analyses of COPD patients aged $\geqslant 40$ years at diagnosis ( $62 \%$ of COPD patients, $n=344$ ) showed no significant associations between livestock farm exposures and COPD prevalence (online supplementary 
TABLE 3 Association between livestock farm exposures and current wheeze within subgroups of patients (based on questionnairel

\begin{tabular}{|c|c|c|c|}
\hline & \multicolumn{3}{|c|}{ Wheezing or whistling on chest in last 12 months } \\
\hline Subjects $n$ & 322 & 748 & 670 \\
\hline \multicolumn{4}{|l|}{ Exposure } \\
\hline \multicolumn{4}{|l|}{ Presence of livestock farms } \\
\hline Within $100 \mathrm{~m}$ & $0.93(0.25-3.54)$ & $0.61(0.30-1.23)$ & $0.80(0.46-1.37)$ \\
\hline Within $500 \mathrm{~m}$ & $1.35(0.96-1.91)$ & $0.93(0.74-1.15)$ & $0.89(0.74-1.06)$ \\
\hline Pigs & $1.05(0.66-1.68)$ & $1.08(0.81-1.44)$ & $0.90(0.72-1.14)$ \\
\hline Poultry & $1.30(0.76-2.23)$ & $1.17(0.86-1.61)$ & $1.27(0.99-1.63)$ \\
\hline Cattle & $1.46(0.99-2.16)$ & $0.84(0.67-1.07)$ & $0.88(0.73-1.07)$ \\
\hline Goats & $0.69(0.14-3.40)$ & $0.79(0.30-2.10)$ & $0.80(0.38-1.71)$ \\
\hline Mink & $2.68(0.27-26.29)$ & $2.05(0.63-6.65)$ & $0.71(0.34-1.47)$ \\
\hline \multicolumn{4}{|l|}{ Presence of farm animals in $1000 \mathrm{~m}$ (yes or no) } \\
\hline Mink & $1.09(0.53-2.28)$ & $0.88(0.56-1.39)$ & $1.19(0.83-1.71)$ \\
\hline \multicolumn{4}{|l|}{ Distance to the nearest farm (quartiles) } \\
\hline$>640 \mathrm{~m}$ & 1 & 1 & 1 \\
\hline $450-640 \mathrm{~m}$ & $2.17(1.32-3.57)$ & $0.94(0.69-1.27)$ & $1.14(0.89-1.46)$ \\
\hline $290-450 \mathrm{~m}$ & $1.65(1.05-2.59)$ & $0.88(0.65-1.19)$ & $0.89(0.70-1.14)$ \\
\hline$<290 \mathrm{~m}$ & $1.45(0.90-2.35)$ & $0.91(0.67-1.23)$ & $0.99(0.77-1.27)$ \\
\hline Test for trend & 0.14 & 0.48 & 0.46 \\
\hline \multicolumn{4}{|l|}{ Number of livestock farms in $1000 \mathrm{~m}$ (quartiles) } \\
\hline$<4$ & 1 & 1 & 1 \\
\hline $4-7$ & $0.96(0.61-1.51)$ & $0.76(0.57-1.02)$ & $0.96(0.76-1.22)$ \\
\hline $7-11$ & $1.01(0.64-1.59)$ & $0.81(0.60-1.08)$ & $0.83(0.65-1.05)$ \\
\hline$>11$ & $1.71(1.01-2.89)$ & $0.93(0.67-1.28)$ & $0.90(0.70-1.15)$ \\
\hline
\end{tabular}

table S5). However, distance to the nearest farm was still significantly associated with wheezing among COPD patients (290-450 m (Q3) OR 2.18, 95\% CI 1.21-3.93) and 450-640 m (Q2) OR 1.89, 95\% CI 1.03-3.47). The presence of $>11$ farms within $1000 \mathrm{~m}$ (Q4) was also still associated with wheezing among COPD patients (OR 2.88, 95\% CI 1.36-6.11). The association between the presence of cattle within $500 \mathrm{~m}$ and usage of ICS among COPD patients was attenuated. However, the positive association between $>11$ farms within $1000 \mathrm{~m}$ and the usage of ICS among COPD patients became significant (OR 2.15, 95\% CI 1.02-4.53).

\section{Discussion}

We found inverse associations between the proximity to livestock farms and self-reported asthma, COPD and allergic rhinitis among neighbouring residents. This suggests a protective effect of livestock farm exposures on respiratory health. However, current wheezing and usage of ICS among COPD patients were positively associated with indicators of livestock farm exposures. This may indicate an increased risk of exacerbations among COPD patients who have a high exposure to livestock farm emissions.

The inverse associations between livestock farm exposures and respiratory diseases in neighbouring residents confirm the study by SMIT et al. [20] in 92548 individuals in the same area using GP EMRs instead of questionnaires. Most studies on proximity to livestock farms show adverse respiratory health 


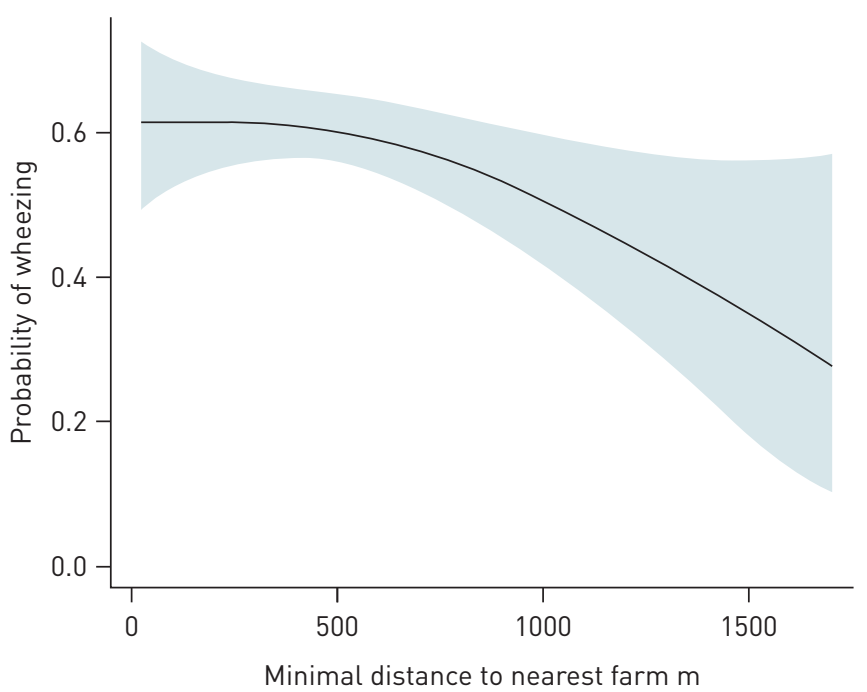

FIGURE 2 Smoothed plots representing associations of the minimal distance to the nearest farm and wheezing in chronic obstructive pulmonary disease patients; significance of smooth terms $p=0.06$.

effects among neighbouring residents [14-19]. Several studies [15, 16, 18, 28] were performed in North Carolina (USA) where industrial hog farms cause widespread pollution. Farm characteristics and the management of manure in North Carolina [29] differs from our study area, which may result in different exposures. Furthermore, hog farms in North Carolina are clustered in low-income minority communities. Therefore, the results of these studies may not be directly comparable with ours.

An explanation for the protective effect of farms could be migration of people with respiratory health problems from rural areas to urban areas. However, we found that asthma and COPD patients living in close proximity to farms deregistered less frequently from the GP registers (based on EMR data over 4 years (2009-2012)) than asthmatics and COPD patients who live at a greater distance from farms. Moreover, asthma and COPD patients showed a similar relationship between distance from livestock farms and the number of years they had lived at their present address compared with the non-patient population (online supplementary methods S2 and S3 and fig. S1). Together these analyses do not give any indication that selective migration due to respiratory health status might explain the associations observed in this study.

Higher and more diverse environmental exposures to microbial components have been attributed to a protective effect on IgE-mediated allergies and asthma in childhood [11, 30]. The inverse association between livestock farm exposures and COPD prevalence has been observed before by SMIT et al. [20], who used EMR data. We found moderate agreement ( $\kappa$ 0.58, 95\% CI 0.54-0.62) between self-reported COPD and COPD based on EMRs. Although there are some inconsistencies between the COPD definitions, the associations were similar in terms of magnitude and direction. The observed protective effect on COPD is not easily explained. We did not have information on potentially confounding farm exposures in childhood, which could partly explain the observed protective effect on asthma and allergy, and possibly COPD. However, several studies have shown that farm exposures during adulthood may also protect against atopy and allergic asthma [31-33]. In the present study we had to rely on self-reported nasal allergy as a proxy for atopy, which might explain why we did not observe pronounced differences in associations between farm exposures and atopic and nonatopic asthma. The second aim of the present study was to explore respiratory symptoms in susceptible subgroups. We found support for the hypothesis that patients with a chronic lung disease may be more susceptible for livestock farm exposures. Increased symptom reporting associated with several indicators of livestock farm exposures in COPD patients could indicate an elevated risk of exacerbations. We did not find this in adult asthma or nasal allergy patients. In occupational settings, an increased risk of COPD is reported for livestock farmers compared with crop farmers [34], and dust and endotoxin exposure showed a dose-response relationship with COPD in never-smoking animal farmers [35]. Farmers are exposed to much higher levels than non-farming residents, since exposure levels inside stables are considerably higher than outside. However, elevated levels of particles with a $50 \%$ cut-off aerodynamic diameter of $10 \mu \mathrm{m}$ and microbial agents such as endotoxin emitted from stables have been measured 200-250 $\mathrm{m}$ downwind of livestock farms [7, 8]. Therefore, increased farm-related air pollution could lead to airway inflammation in neighbouring COPD patients, and might explain the associations we found with wheezing and usage of ICS. 
Furthermore, increased morbidity in individuals with COPD near livestock farms might be explained by environmental exposures to pathogenic micro-organisms from livestock farms, leading to exacerbations with an infectious aetiology [36]. However, infections with specific zoonotic pathogens were not very common in patients with community-acquired pneumonia living in an area with many livestock farms [37]. Nonpathogenic micro-organisms might contribute through their toxins, such as endotoxins, resulting in inflammatory responses [21]. Moreover, DicKson et al. [38] suggested that exacerbations of COPD are occasions of respiratory dysbiosis: disorder and dysregulation of the microbial ecosystem of the respiratory tract, coupled with a dysregulated host immune response. It could be speculated that changes in the lung microbiome as a result of long-term environmental exposures could play a role in these adverse respiratory effects as well.

The medical information available for nonresponders is a unique feature of the VGO study, and enabled us to compare characteristics of nonresponders and responders. We were able to demonstrate that selection bias did not affect associations between farm exposures and respiratory disease, which was available for invited subjects through the EMRs. The prevalence of self-reported asthma, COPD and nasal allergies (table 2) was higher than that based on EMRs. In particular, the prevalence of current asthma was higher than might be expected in a rural setting. Both methods have their advantages and disadvantages, but estimation of respiratory symptom prevalence by the ECRHS questionnaire is a more commonly used method in epidemiological studies. Misclassification of individual exposure estimates is likely to be limited because we used information on livestock farm licences from the same year in which the questionnaires were collected. We did not take into account the influence of wind direction on exposure. The average wind direction in the Netherlands is south-westerly, but the wind speed and direction varies across the year. Therefore we do not expect that wind direction will greatly influence these results. More refined exposure assessment approaches are under development, which take into account meteorological circumstances, and will be deployed in subsequent phases of this study.

Individual exposure estimates were calculated based on the home address and most people do not spend $24 \mathrm{~h}$ a day at home. However, in Europe, adults spend the majority of their time indoors at home (5666\%) [39]. Therefore the home address should be a good and convenient predictor to estimate exposure. It could be argued that an analysis in retired participants would lead to more accurate exposure estimates, leading to less attenuation bias. However, a sensitivity analysis in those aged $>65$ years did not yield different odds ratios (data not shown).

This is an explorative study, involving multiple exposure variables. The results should be interpreted with caution, given the number of tests performed. Nevertheless, the observed positive and negative trends seem to be consistent across several exposure variables.

In conclusion, we found an inverse association between different indicators of livestock farm exposure from livestock farms and self-reported current asthma and COPD among neighbouring residents. This suggests a protective effect from livestock farm emissions, possibly explained by higher and more diverse environmental exposures to microbial components. However, current wheezing and usage of ICS among COPD patients was positively associated with several indicators of livestock farm exposures, suggesting an increased risk of exacerbations in a susceptible group.

\section{Acknowledgements}

The authors would like to thank Elsbeth de Leeuw-Stravers (Institute for Health Services Research, NIVEL, Utrecht, the Netherlands) for her assistance with data collection.

\section{References}

1 Heederik D, Sigsgaard T, Thorne PS, et al. Health effects of airborne exposures from concentrated animal feeding operations. Environ Health Perspect 2007; 115: 298-302.

2 Koopmans M, Wilbrink B, Conyn M, et al. Transmission of H7N7 avian influenza A virus to human beings during a large outbreak in commercial poultry farms in the Netherlands. Lancet 2004; 363: 587-593.

3 van der Hoek W, Morroy G, Renders NH, et al. Epidemic Q fever in humans in the Netherlands. Adv Exp Med Biol 2012; 984: 329-364.

4 Schulze A, van Strien R, Ehrenstein V, et al. Ambient endotoxin level in an area with intensive livestock production. Ann Agric Environ Med 2006; 13: 87-91.

5 Williams DL, Breysse PN, McCormack MC, et al. Airborne cow allergen, ammonia and particulate matter at homes vary with distance to industrial scale dairy operations: an exposure assessment. Environ Health 2011; 10: 72.

6 Thorne PS, Ansley AC, Perry SS. Concentrations of bioaerosols, odors, and hydrogen sulfide inside and downwind from two types of swine livestock operations. J Occup Environ Hyg 2009; 6: 211-220.

7 Dungan RS, Leytem AB, Bjorneberg DL. Concentrations of airborne endotoxin and microorganisms at a 10,000-cow open-freestall dairy. J Anim Sci 2011; 89: 3300-3309.

8 Heederik DJJ, Ijzermans CJ. Potential Effects of Intensive Livestock Farming on Neighboring Residents' Health. Utrecht, IRAS, Utrecht University, NIVEL, RIVM, 2011. 
Lawson JA, Dosman JA, Rennie DC, et al. The association between endotoxin and lung function among children and adolescents living in a rural area. Can Respir J 2011; 18: e89-e94.

10 Genuneit J. Exposure to farming environments in childhood and asthma and wheeze in rural populations: a systematic review with meta-analysis. Pediatr Allergy Immunol 2012; 23: 509-518.

11 Ege MJ, Mayer M, Normand AC, et al. Exposure to environmental microorganisms and childhood asthma. $N$ Engl J Med 2011; 364: 701-709.

12 von Mutius E, Radon K. Living on a farm: impact on asthma induction and clinical course. Immunol Allergy Clin North Am 2008; 28: 631-647.

13 Lluis A, Schaub B. Lesson from the farm environment. Curr Opin Allergy Clin Immunol 2012; 12: 158-163.

14 Sigurdarson ST, Kline JN. School proximity to concentrated animal feeding operations and prevalence of asthma in students. Chest 2006; 129: 1486-1491.

15 Mirabelli MC, Wing S, Marshall SW, et al. Asthma symptoms among adolescents who attend public schools that are located near confined swine feeding operations. Pediatrics 2006; 118: e66-e75.

16 Elliott L, Yeatts K, Loomis D. Ecological associations between asthma prevalence and potential exposure to farming. Eur Respir J 2004; 24: 938-941.

17 Pavilonis BT, Sanderson WT, Merchant JA. Relative exposure to swine animal feeding operations and childhood asthma prevalence in an agricultural cohort. Environ Res 2013; 122: 74-80.

18 Schinasi L, Horton RA, Guidry VT, et al. Air pollution, lung function, and physical symptoms in communities near concentrated swine feeding operations. Epidemiology 2011; 22: 208-215.

19 Radon K, Schulze A, Ehrenstein V, et al. Environmental exposure to confined animal feeding operations and respiratory health of neighboring residents. Epidemiology 2007; 18: 300-308.

20 Smit LA, Hooiveld M, van der Sman-de Beer F, et al. Air pollution from livestock farms, and asthma, allergic rhinitis and COPD among neighbouring residents. Occup Environ Med 2014; 71: 134-140.

21 Harting JR, Gleason A, Romberger DJ, et al. Chronic obstructive pulmonary disease patients have greater systemic responsiveness to ex vivo stimulation with swine dust extract and its components versus healthy volunteers. J Toxicol Environ Health A 2012; 75: 1456-1470.

22 Sigurdarson ST, O'Shaughnessy PT, Watt JA, et al. Experimental human exposure to inhaled grain dust and ammonia: towards a model of concentrated animal feeding operations. Am J Ind Med 2004; 46: 345-348.

23 Smit LA, van der Sman-de Beer F, Opstal-van Winden AW, et al. Q fever and pneumonia in an area with a high livestock density: a large population-based study. PLoS One 2012; 7: e38843.

24 Jarvis D, Newson R, Burney $\mathrm{P}$, et al. Change in respiratory symptoms in young adults as they age: European community respiratory health survey 3 (ECRHS 3). Eur Respir J 2013; 42: Suppl. 57, 1809.

25 Verheij RA. NIVEL Zorgregistraties Eerste Lijn: Huisarts. [Netherlands Primary Care Database: General Practitioners]. www.nivel.nl/node/3467 Date last accessed: January 28, 2015. Date last updated: 2014.

26 Lamberts H, Wood H. The International Classification of Primary Care. Oxford, Oxford University Press, 1987.

27 Pekkanen J, Lampi J, Genuneit J, et al. Analyzing atopic and non-atopic asthma. Eur J Epidemiol 2012; 27: 281-286.

28 Mirabelli MC, Wing S, Marshall SW, et al. Race, poverty, and potential exposure of middle-school students to air emissions from confined swine feeding operations. Environ Health Perspect 2006; 114: 591-596.

29 Nicole W. CAFOs and environmental justice: the case of North Carolina. Environ Health Perspect 2013; 121 : A182-A189.

30 Von Ehrenstein OS, Von Mutius E, Illi S, et al. Reduced risk of hay fever and asthma among children of farmers. Clin Exp Allergy 2000; 30: 187-193.

31 Kauffmann F, Oryszczyn MP, Maccario J. The protective role of country living on skin prick tests, immunoglobulin $\mathrm{E}$ and asthma in adults from the Epidemiological study on the Genetics and Environment of Asthma, bronchial hyper-responsiveness and atopy. Clin Exp Allergy 2002; 32: 379-386.

32 Eduard W, Douwes J, Omenaas E, et al. Do farming exposures cause or prevent asthma? Results from a study of adult Norwegian farmers. Thorax 2004; 59: 381-386.

33 Smit LA, Heederik D, Doekes G, et al. Occupational endotoxin exposure reduces the risk of atopic sensitization but increases the risk of bronchial hyperresponsiveness. Int Arch Allergy Immunol 2010; 152: 151-158.

34 Eduard W, Pearce N, Douwes J. Chronic bronchitis, COPD, and lung function in farmers: the role of biological agents. Chest 2009; 136: 716-725.

35 Monsó E, Riu E, Radon K, et al. Chronic obstructive pulmonary disease in never-smoking animal farmers working inside confinement buildings. Am J Ind Med 2004; 46: 357-362.

36 Beasley V, Joshi PV, Singanayagam A, et al. Lung microbiology and exacerbations in COPD. Int J Chron Obstruct Pulmon Dis 2012; 7: 555-569.

37 Huijskens EGW, Smit LAM, Rossen JWA, et al. Evaluation of patients with community-acquired pneumonia caused by zoonotic pathogens in an area with a high density of animal farms. Zoonoses Public Health 2015 (In press).

38 Dickson RP, Martinez FJ, Huffnagle GB. The role of the microbiome in exacerbations of chronic lung diseases. Lancet 2014; 384: 691-702.

39 Schweizer C, Edwards RD, Bayer-Oglesby L, et al. Indoor time-microenvironment-activity patterns in seven regions of Europe. J Expo Sci Environ Epidemiol 2007; 17: 170-181. 